\title{
Critical Review of the Pivotal Studies of Four rFVIII Products for the Treatment of Hemophilia A Patients: The Role of Octocog Alfa
}

\author{
Matteo Nicola Dario Di Minno ${ }^{1}$, Lucia Sara D’Angiolella ${ }^{2}$, Paolo Angelo Cortesi², \\ Angelo Claudio Molinari ${ }^{3}$, Lorenzo Giovanni Mantovani ${ }^{2}$ \\ Department of Translational Medical Sciences, Federico II University, Naples, Italy \\ Research Centre on Public Health (CESP), University of Milan - Bicocca, Milan, Italy \\ Regional Reference Center for Hemorrhagic Diseases, Thrombosis and Haemostasis Unit, G. Gaslini Children's Hospital, \\ Genoa, Italy
}

\begin{abstract}
INTRODUCTION: Hemophilia A is a rare congenital bleeding disorder caused by a deficiency of clotting factor VIII (FVIII). The severe form of the disease is characterized by spontaneous bleeds, especially into the joints. Prophylaxis, based on regularly intravenous administration of the missing factor to avoid hemorrhages, represents the gold standard of treatment. In recent years, new products that significantly improve the treatment management options for patients with hemophilia have become available in the market.

OBJECTIVE: To critically evaluate the pivotal studies of recombinant FVIII (rFVIII) products, approved in Europe within the first half of 2018 having obtained the indication for a prophylaxis dosing regimen based also on a twice weekly infusion frequency or even less, highlighting their limitations or strengths.

METHODS: A systematic literature search was conducted, and several databases (PubMed and Embase) were consulted. RESULTS: Nine clinical trials involving patients with severe hemophilia A without inhibitor were included in this analysis. Four rFVIII products (Elocta ${ }^{\circledR}$, Biogen, Cambridge, MA, USA; Kovaltry ${ }^{\circledR}$, Bayer HealthCare Pharmaceuticals, Germany; Afstyla $^{\circledR}$, CSL Behring GmbH, Germany; Adynovi ${ }^{\circledR}$, Baxalta Innovation GmbH, Austria) with different pharmacokinetic profiles were evaluated. The trials included in this analysis had different designs and heterogeneous methods were utilized to assess the study outcomes. The baseline characteristics of the patients enrolled in the studies were also often different and sometimes not adequately described. LEOPOLD II, a trial to compare prophylaxis to on-demand therapy with an unmodified rFVIII product (Kovaltry ${ }^{\circledR}$, octocog alfa), was the only completely randomized trial that enrolled a more critical patient population in terms of compromised joint condition than the other studies. Based on these side-by-side comparison, Octocog alfa reported similar efficacy, in terms of annualized bleeding rate, to the other rFVIII products, including extended half-life.

CONCLUSIONS: Even without structural modifications, octocog alfa may be considered a useful treatment option for two times a week prophylaxis in a selected population of haemophilia patients.
\end{abstract}

\section{Keywords}

Hemophilia; Recombinant factor VIII; Kovaltry ${ }^{\circledR}$; Critical review

\section{INTRODUCTION}

Hemophilia $\mathrm{A}$ is a rare congenital bleeding disorder caused by a reduced or absent production of clotting factor VIII (FVIII). It is characterized by bleeding episodes predominantly into the joints, muscles and soft tissues, which can occur spontaneously or following minor trauma $[1,2]$. The treatment of hemophilia A is a replacement therapy based on the intravenous administration of the deficient factor concentrate (FVIII), which can be used on-demand (i.e. from when the bleed occurs until its resolution) or under a prophylaxis regimen (i.e. administered at regular intervals, even in the absence of bleed, to prevent its onset) [3]. To date, the efficacy of prophylaxis compared to on-demand treatment in preventing joint damage and reducing the progression of hemophilic arthropathy is widely recognized and, for this reason, it represents the gold standard of treatment in children born with severe hemophilia A.

Corresponding author Lucia Sara D'Angiolella lucia.dangiolella@unimib.it

Received: 12 December 2019 Accepted: 21 March 2020 Published: 3 April 2020 
Due to the short half-life of FVIII of approximately 10-12 hours, prophylaxis usually requires intravenous administrations every other day or three times a week [4-6], thereby representing a significant burden for patients. In recent years, several products have been developed that have significantly improved the treatment management of the patients with hemophilia and allowed clinicians to use a personalized therapeutic approach, adjusted for the patients characteristics and attitudes and able to meet their needs. These products, realized through molecular structure modifications (e.g. fusion with the Immunoglobulin Fc fragment, PEGylation and the creation of a single chain) or innovative production techniques (e.g. the co-expression of the Human Heat Shock Protein 70, HSP70), show an improved pharmacokinetic profile which have allowed, in some cases, a reduction in the number of prophylaxis infusions required or to provide more effective protection from bleed while leaving the frequency of administration unchanged [7]. While improved pharmacokinetic properties represent an important advance in the management of hemophilia A patients, they remain secondary to clinical efficacy [8], but represent an additional "piece of the puzzle" to individualize prophylaxis based on the characteristics of the drug and the individual patient's disease course (bleeding phenotype, presence/absence of joint damage, level of physical activity and adherence to prescribed treatment). This individualized therapeutic approach, together with the rationalization of consumption and the optimization of outcomes for each patient, is becoming one of the most important elements to consider for an appropriate treatment $[9,10]$.

Despite the availability of new recombinant FVIII (rFVIII) products, there are no head-tohead studies directly comparing the clinical efficacy of the different products. Clinicians can guide their choices only with the indirect comparison between drugs, which can be performed through a critical evaluation of the individual pivotal trials, in order to understand their value, main features, and differences [11].

In the present work, a critical evaluation was carried out of the pivotal studies of the rFVIII products approved in Europe within the first half of 2018 which, due to their clinical efficacy and improved pharmacokinetic profile, obtained an indication for a prophylaxis dosing regimen also including a twice weekly infusion schedule, or even less. The aim of this analysis was to critically evaluate the methods and results of the clinical studies, highlighting any limitations or strengths.

\section{METHODS}

Pivotal studies of rFVIII products were identified through a systematic literature search, performed on two bibliographic databases (PubMed and Embase). Studies not published in English language were excluded from the evaluation. The analysis included only the full-texts of the pivotal studies concerning rFVIII products approved in Europe within the first half of 2018 for the treatment and prevention of hemorrhages in patients with hemophilia A, with prophylaxis regimens based on twice weekly infusions, or less. From each study, the following data were extracted: the baseline characteristics of the enrolled population (age, proportion of patients with target joints, proportion of patients on prophylaxis before the study enrollment and number of bleeds in the 12 months prior to enrollment), the clinical efficacy results (annualized bleeding rate - ABR, number of bleeds and proportion of patients with zero bleeds), and the consumption data for the most representative therapeutic regimens approved in $\mathrm{Eu}-$

\begin{tabular}{|c|c|c|}
\hline Product & Drug & Pivotal study \\
\hline \multicolumn{3}{|c|}{ Studies conducted on cohorts of subjects aged $\geq 12$} \\
\hline Elocta $^{\circledast}$ & Efmoroctocog alfa & A-LONG [12] \\
\hline Kovaltry $^{\circledR}$ & Octocog alfa & $\begin{array}{l}\text { LEOPOLD I; LEOPOLD ॥ } \\
{[14,15]}\end{array}$ \\
\hline Afstyla ${ }^{\circledR}$ & Lonoctocog alfa & AFFINITY [17] \\
\hline Adynovi ${ }^{\circledR}$ & Rurioctocog alfa pegol & PROLONG-ATE [19] \\
\hline \multicolumn{3}{|c|}{ Studies conducted on cohorts of subjects aged $<12$} \\
\hline Elocta $^{\circledast}$ & Efmoroctocog alfa & A-LONG KIDS [13] \\
\hline Kovaltry ${ }^{\circledR}$ & Octocog alfa & LEOPOLD KIDS [16] \\
\hline Afstyla $^{\circledR}$ & Lonoctocog alfa & AFFINITY KIDS [18] \\
\hline Adynovi $^{\circledR}$ & Rurioctocog alfa pegol & PROLONG-ATE KIDS [20] \\
\hline
\end{tabular}

Table I. Overview of the analyzed studies rope (mean and/or median weekly and annual dose). The results of the selected studies were critically evaluated, extracted and compared.

\section{RESULTS}

The pivotal studies of efmoroctocog alfa (Elocta $^{\circledR}$, Biogen, Cambridge, MA, USA) $[12,13]$, octocog alfa $\left(\right.$ Kovaltry $^{\circledR}$, Bayer HealthCare Pharmaceuticals, Germany) [1416], lonoctocog alfa (Afstyla ${ }^{\circledR}$, CSL Behring $\mathrm{GmbH}$, Germany) [17,18] and rurioctocog alfa pegol (Adynovi ${ }^{\circledR}$, Baxalta Innovation $\mathrm{GmbH}$, Austria) $[19,20]$ were analyzed. Coherent with literature evidences [21], efmoroctocog alfa and rurioctocog alfa pegol were defined as extended half-life (EHL) rF- 
VIII products, while octocog alfa and lonoctocog alfa were considered as standard half-life (SHL) rFVIII products. A total of nine clinical studies conducted in adolescent/adult $(\geq 12$ years) and pediatric ( $<12$ years) patients with severe hemophilia A without inhibitor were evaluated (Table I). Five studies enrolled patients aged $\geq 12[12,14,15,17,19]$, and four studies patients aged $<12[13,16,18,20]$.

\section{Population aged $\geq 12$}

The efficacy of efmoroctocog alfa was evaluated in a phase III, open-label, partially randomized clinical trial (A-LONG) [12], which compared on-demand treatment with two prophylactic treatment regimens (an individualized regimen and a weekly regimen). A total of 142 patients received prophylaxis treatment: 118 were assigned to the individualized arm, with an infusion scheme that consisted of the administration of $25 \mathrm{IU} / \mathrm{kg}$ on Day 1 and 50 IU/kg on Day 4, followed by 25-65 IU/kg every 3-5 days, based on individual needs and the doctor's judgment. Only 24 patients were assigned to the weekly arm, which provided for an infusion of $65 \mathrm{IU} / \mathrm{kg}$ once a week. At the end of the study, patients in the individualized arm reported a mean infusion interval of 3.9 days: $29.9 \%$ of patients received prophylaxis twice a week, $33.3 \%$ of patients received an infusion every three days, $3.4 \%$ every four days and the remaining $33.3 \%$ every five days [12].

The efficacy of octocog alfa was evaluated in two clinical studies: LEOPOLD I [14] and LEOPOLD II [15]. LEOPOLD I [14] was a phase III, open-label study, which enrolled 62 patients. All patients included in the study were treated on prophylaxis with $20-50 \mathrm{IU} / \mathrm{kg}$ of octocog alfa, two $(n=18)$ or three times $(n=44)$ per week, at the discretion of the physician, and were followed prospectively for one year. LEOPOLD II [15] was a phase II/III, openlabel, randomized study, with a 12-month follow-up, which enrolled 80 patients: 21 received an on-demand treatment and 59 were randomized to receive prophylaxis with $20-30 \mathrm{IU} / \mathrm{kg}$ of octocog alfa twice a week $(n=28)$, or 30-40 IU/kg three times a week $(n=31)$.

The efficacy of lonoctocog alfa was evaluated in the AFFINITY study [17], a phase II/ III, open-label study which enrolled 173 patients: 146 underwent a prophylaxis with different infusion regimens, based on the administration of 20-40 IU/ $\mathrm{kg}$ of lonoctocog alfa every other day $(n=9)$ or $20-50 \mathrm{IU} / \mathrm{kg}$ two $(n=47)$ or three $(n=79)$ times per week or other regimens $(n=11)$ established at the discretion of the investigator. The remaining part of the sample $(n=27 / 173)$ received on-demand treatment.

The efficacy of rurioctocog alfa pegol was evaluated in the PROLONG-ATE study [19], a phase II/III, open-label study which enrolled 137 patients, of whom 120 were treated on prophylaxis, with a fixed scheme of $45 \pm 5 \mathrm{IU} / \mathrm{kg}$ twice a week, and 17 received on-demand treatment.

Overall, the studies involved a sample of 530 adolescent/adult patients ( $\geq 12$ years of age) with severe hemophilia A, treated on prophylaxis. The sample size of the individual studies was rather heterogeneous, ranging from a minimum of 59 to a maximum of 146 patients $[15,17]$. The most relevant limitation of the selected studies lies in the experimental trials design, since only the LEOPOLD II study [15] was a completely randomized trial. The baseline characteristics of the patients who received prophylaxis are very different between the studies (Table II and Table III): the number of patients on prophylaxis prior to study entry and the proportion of patients with target joints were very variable. In the LEOPOLD II study [15], no patient had received a regular prophylaxis for more than six consecutive months in the five years prior to enrollment, while in the PROLONG-ATE study [19], 82.5\% of patients were already on prophylaxis before enrollment. In the LEOPOLD II study [15], a higher prevalence of target joints than in other studies was reported at baseline $(89.3 \%$ and $90.3 \%$ of the patients treated with two or three infusions per week, respectively, vs $65.0 \%$ of the patients treated twice a week in the PROLONG-ATE study) [19]. Further details, such as the mean number of total and joint bleeds in the 12 months prior to enrollment, were reported only for LEOPOLD I and II $[14,15]$ (Table III). However, all studies have utilized ABR as the primary efficacy outcome, although the methods used for its calculation were very heterogeneous. Almost all of the studies reported the median value for the ABR assessment (Table IV). However, the studies included in this evaluation are often characterized by a relatively low sample size and a follow-up of less than one year; only in the LEOPOLD studies (I and II) [14,15] the follow-up lasted 12 months. To overcome these methodological limitations, specific probabilistic models were used in the other studies for the evaluation of the ABR, including the negative binomial model and the Poisson model. In the A-LONG study [12], patients treated with efmoroctocog alfa in the individualized or weekly prophylaxis arm reported an ABR obtained with a negative binomial model of 2.9 (95\% CI: $2.3-3.7)$ and 8.9 (95\% CI: 5.5-14.5), 
respectively (Table IV). In the AFFINITY study [17], the ABR was calculated using a Poisson probabilistic model, also defined as an approximation of the binomial distribution, and, taking into account all the patients treated on prophylaxis, it resulted equal to 2.6 (95\% CI: 2.3-2.9). In the PROLONG-ATE study [19], a median ABR of 1.9 (IQR: 0.0, 5.8) was reported for the patients on prophylaxis, and no probabilistic model was used, although the duration of the study was less than one year. In the LEOPOLD I and LEOPOLD II studies $[14,15]$, the median ABR referred to all the patients on prophylaxis was 1.0 (IQR: 0.0, 5.1) and 2.0 (IQR: $0.0,7.0)$, respectively.

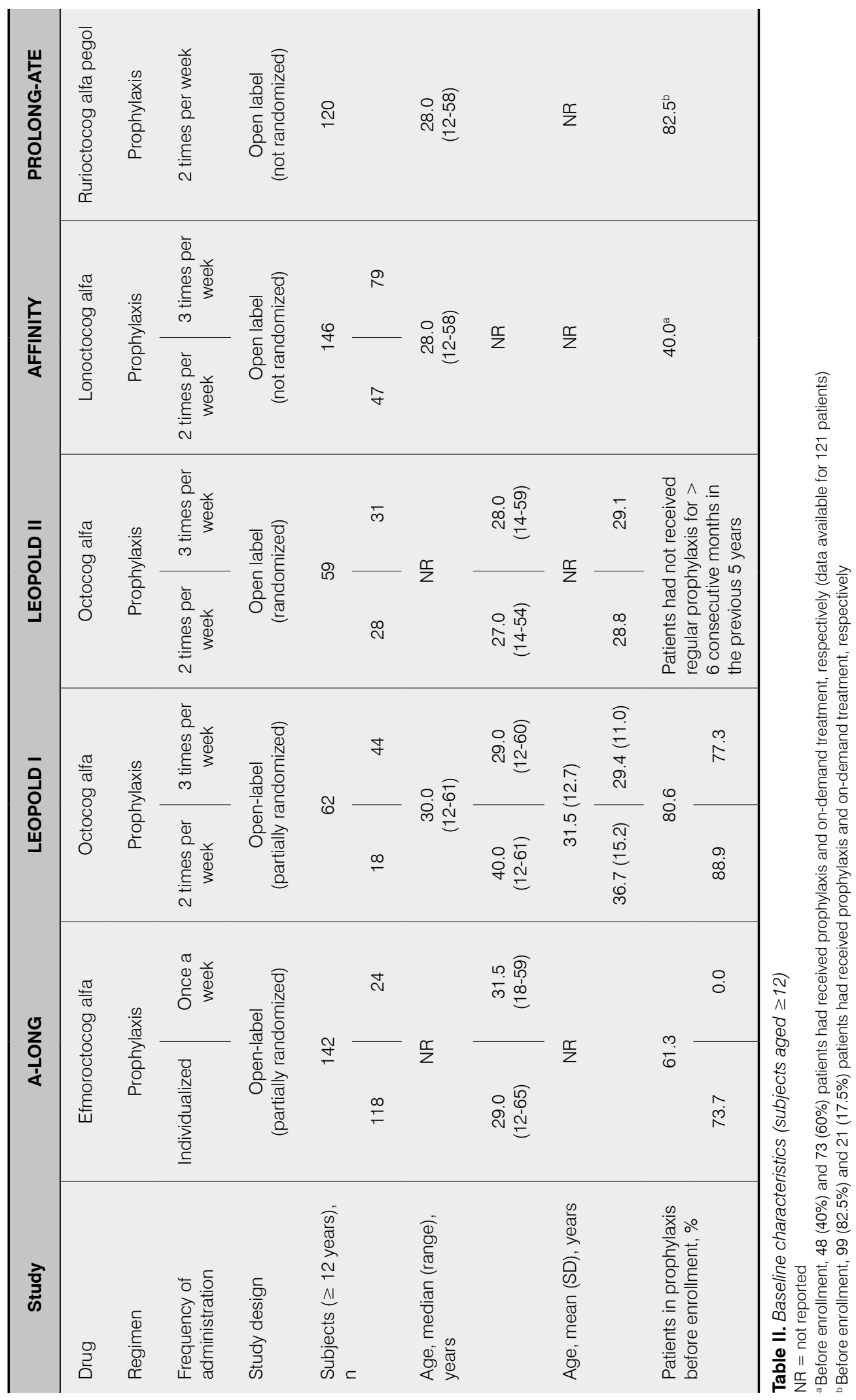




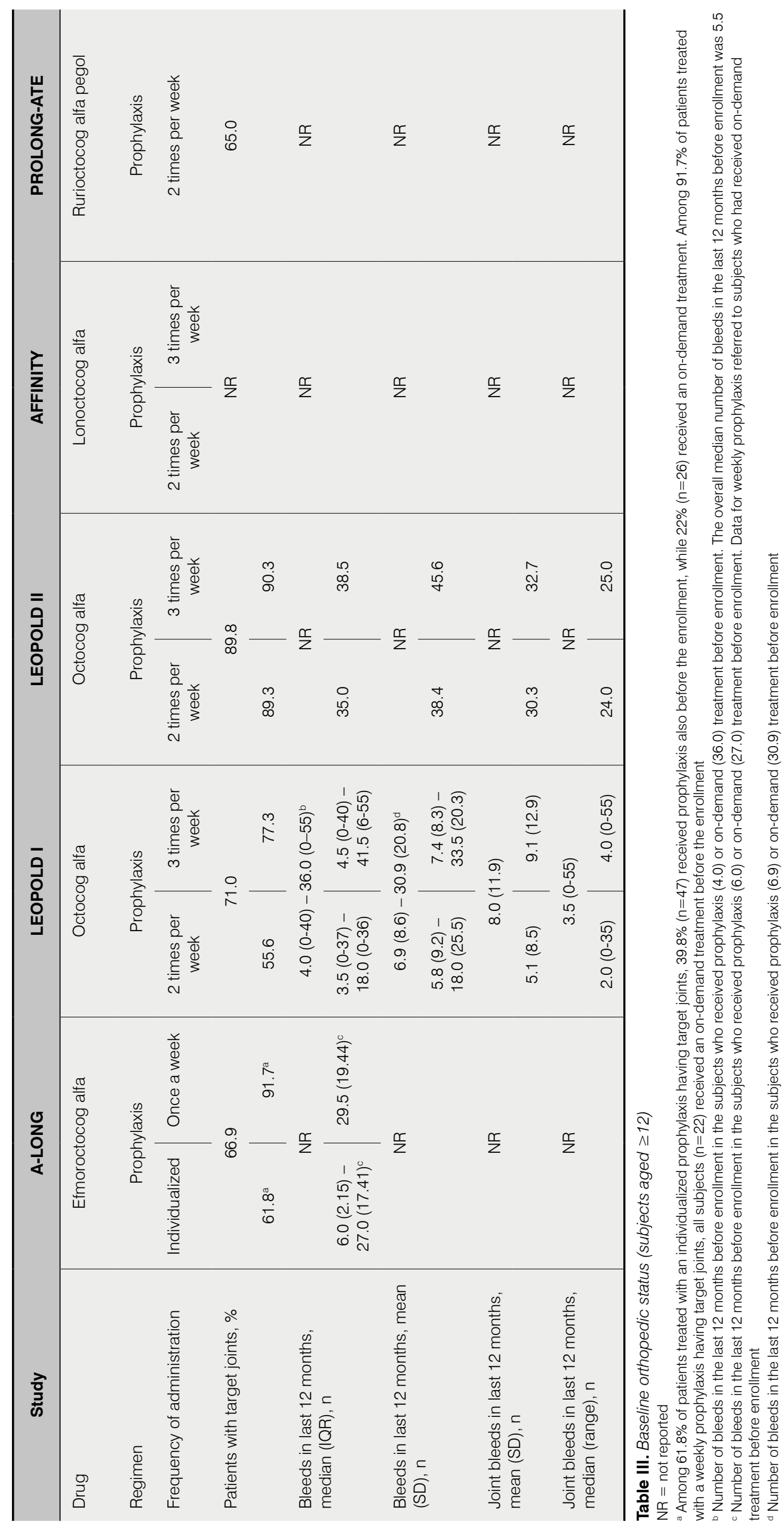




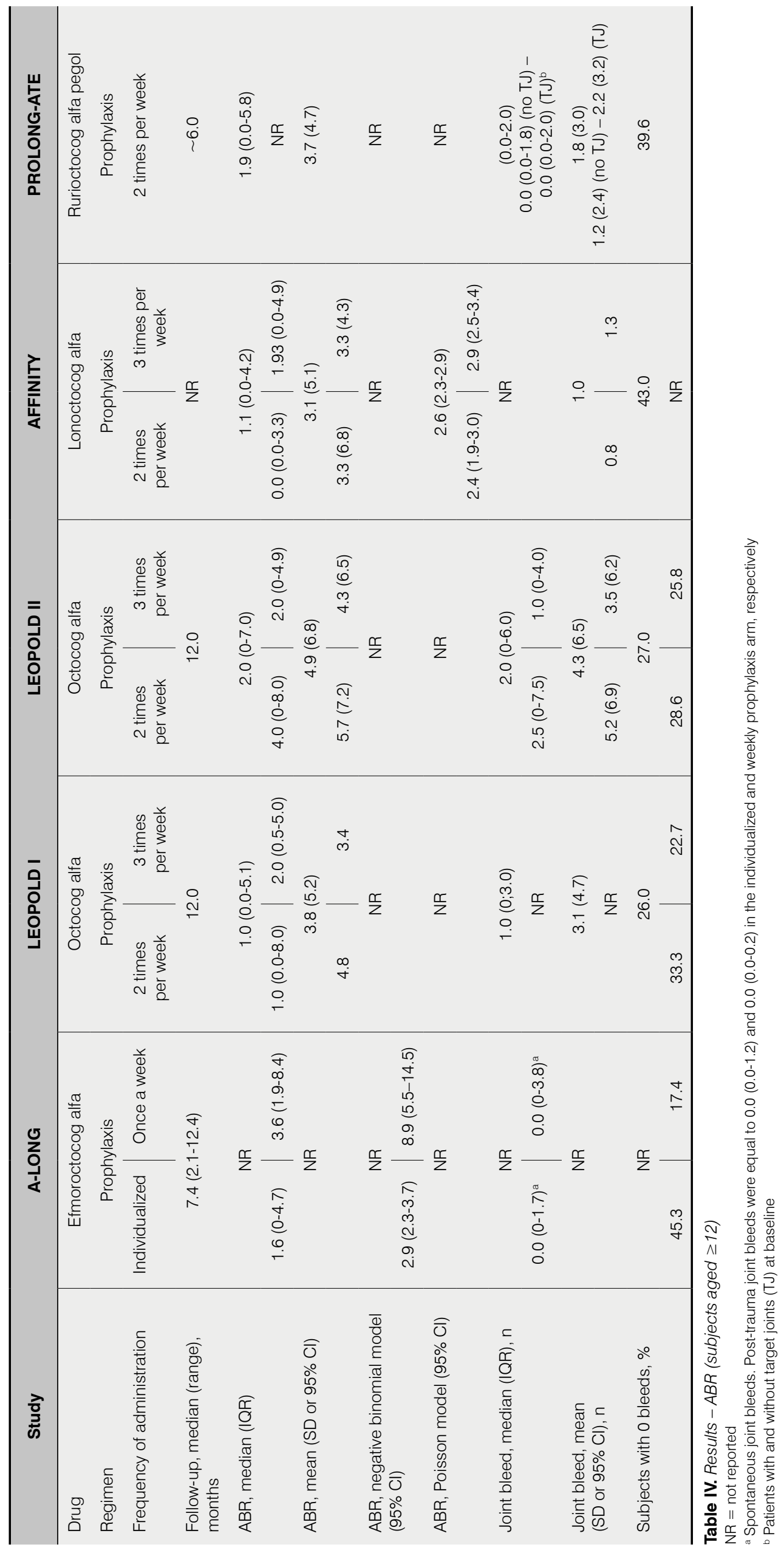




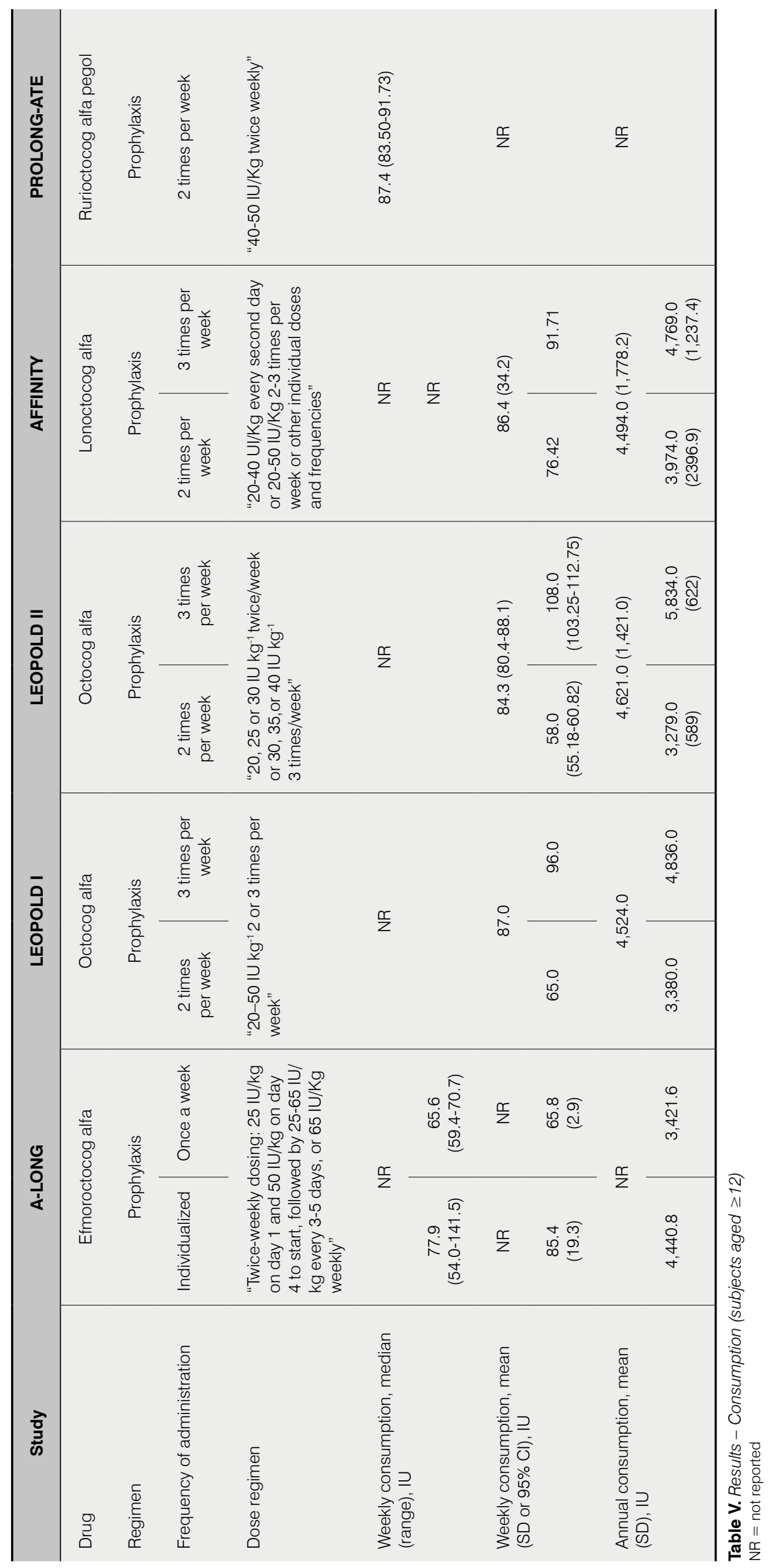




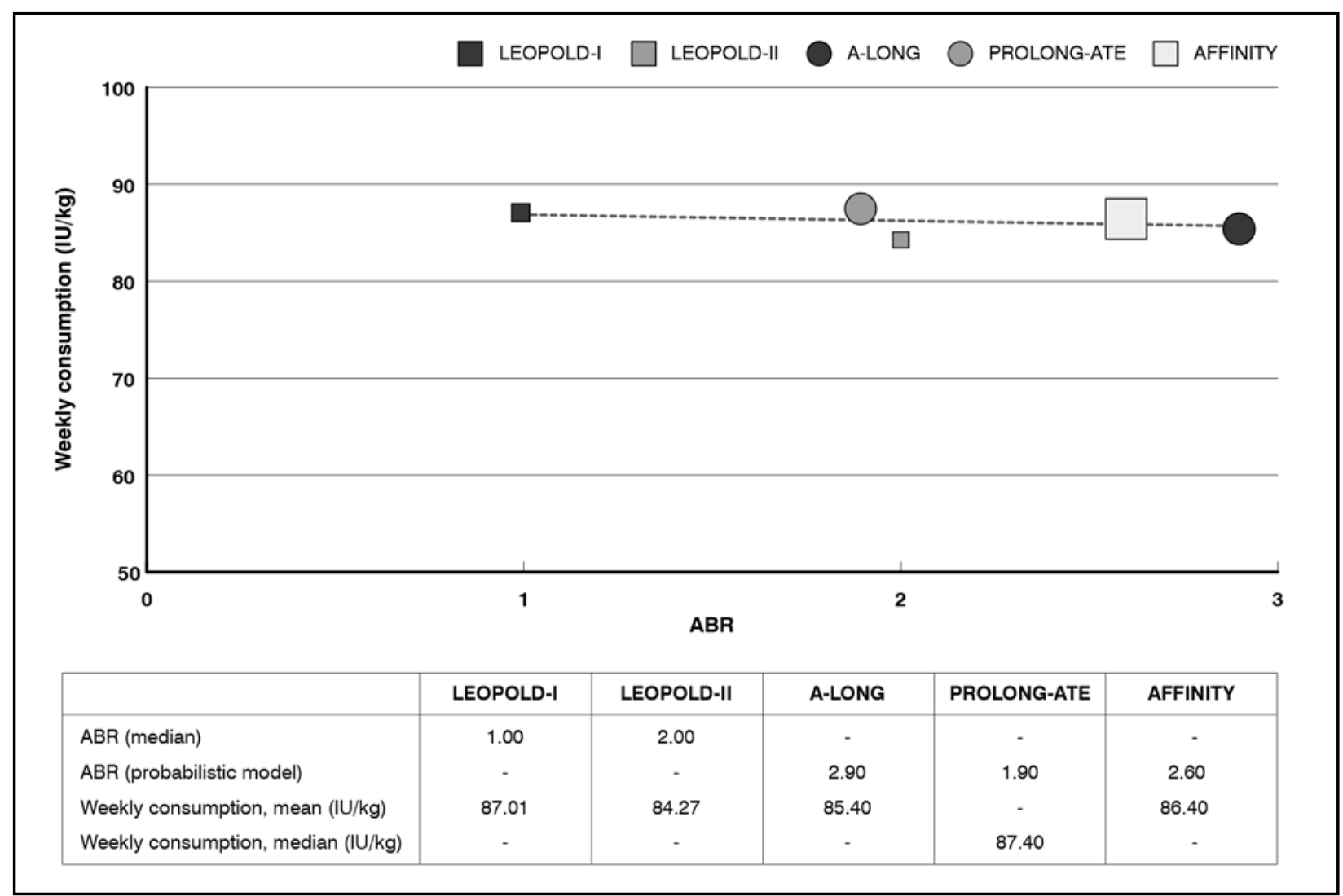

Figure 1. Results - Consumptions and ABR (subjects aged $\geq 12$ )

Note: the dimension of the indicator is directly proportional to the number of subjects enrolled in the study

The mean weekly or annual FVIII consumption during prophylaxis was reported in all studies. Only the PROLONG-ATE study [19] reported the data as a median, which, not necessarily taking into account the dosage distribution per single patient, could represent an underestimation (Table V). The consumption and efficacy data (ABR) of the four $\mathrm{rFVIII}$ products included in this analysis were correlated on a dispersion diagram (Figure 1) and distinguished, on the basis of their pharmacokinetic profiles, in EHL products (efmoroctocog alfa and rurioctocog alfa pegol) and SHL products (octocog alfa and lonoctocog alfa) [21]. Depending on the sample size to which the estimates refer, each product was associated with an indicator whose dimensions are directly proportional to the number of patients enrolled in the study. For each study analyzed, the total ABR was reported, referred to all the patients on prophylaxis, regardless of the infusion regimen. Since the overall data was not reported in the A-LONG study [12], the data of the numerically larger sample of patients, related to individualized prophylaxis, had to be used for this study only. Figure 1 does not show any relationship between $A B R$ and weekly consumption $\left(R^{2}=0.16\right)$. Furthermore, although the differences between the pharmacokinetic profiles and the dosing regimens, among the four $\mathrm{rFVIII}$ products included in the present analysis there was no significant variability regarding the results, neither in terms of ABR, nor of consumption (Table IV and Table V).

\section{Population aged $<12$}

The efficacy of efmoroctocog alfa, octocog alfa, lonoctocog alfa and rurioctocog alfa pegol for the prophylaxis of children with severe hemophilia A without inhibitor was evaluated in four clinical studies: A-LONG KIDS [13], LEOPOLD KIDS [16], AFFINITY KIDS [18] and PROLONG-ATE KIDS [20]. All studies had an open-label design.

The efficacy of efmoroctocog alfa was evaluated in the A-LONG KIDS study [13]. All the enrolled patients $(\mathrm{n}=71)$ received a twice-weekly prophylaxis, based on the administration of $25 \mathrm{IU} / \mathrm{kg}$ on Day 1 and $50 \mathrm{IU} / \mathrm{kg}$ on Day 4, with the possibility of adjusting the dosage up to a maximum of $80 \mathrm{IU} / \mathrm{kg}$ every other day. The LEOPOLD KIDS study [16] enrolled 51 patients, who were treated with $20-50 \mathrm{IU} / \mathrm{kg}$ of octocog alfa at least twice a week; $41.2 \%$ of patients received two infusions per week, $43.1 \%$ three infusions per week, and only $15.7 \%$ of patients received more than three infusions per week. In the AFFINITY KIDS study [18], 81 patients received prophylaxis with $15-50 \mathrm{IU} / \mathrm{kg}$ of lonoctocog alfa, every other day or two-three times 


\begin{tabular}{|c|c|c|c|c|c|c|}
\hline Study & A-LONG KIDS & \multicolumn{2}{|c|}{ LEOPOLD KIDS } & \multicolumn{2}{|c|}{ AFFINITY KIDS } & $\begin{array}{l}\text { PROLONG-ATE } \\
\text { KIDS }\end{array}$ \\
\hline Drug & Efmoroctocog alfa & \multirow{2}{*}{\multicolumn{2}{|c|}{$\begin{array}{l}\text { Octocog alfa } \\
\text { Prophylaxis }\end{array}$}} & \multirow{2}{*}{\multicolumn{2}{|c|}{$\begin{array}{c}\text { Lonoctocog alfa } \\
\text { Prophylaxis }\end{array}$}} & Rurioctocog alfa pegol \\
\hline Regimen & Prophylaxis & & & & & Prophylaxis \\
\hline $\begin{array}{l}\text { Frequency of } \\
\text { administration }\end{array}$ & - & $\begin{array}{l}2 \text { times per } \\
\text { week }\end{array}$ & $\begin{array}{l}>2 \text { times } \\
\text { per week }\end{array}$ & $\begin{array}{l}2 \text { times per } \\
\text { week }\end{array}$ & $\begin{array}{l}>2 \text { times } \\
\text { per week }\end{array}$ & - \\
\hline Study design & $\begin{array}{c}\text { Open-label } \\
\text { (not randomized) }\end{array}$ & \multicolumn{2}{|c|}{$\begin{array}{c}\text { Open-label } \\
\text { (not randomized) }\end{array}$} & \multicolumn{2}{|c|}{$\begin{array}{c}\text { Open-label } \\
\text { (not randomized) }\end{array}$} & $\begin{array}{c}\text { Open-label } \\
\text { (not randomized) }\end{array}$ \\
\hline \multirow[t]{2}{*}{ Subjects, n } & 71 & \multicolumn{2}{|c|}{51} & \multicolumn{2}{|c|}{$81^{a}$} & 66 \\
\hline & & 21 & 30 & 43 & 38 & \\
\hline $\begin{array}{l}\text { Age, median (range), } \\
\text { years }\end{array}$ & $5.0(1-11)$ & \multicolumn{2}{|c|}{$\begin{array}{c}6.0(1-11) \\
\text { NR }\end{array}$} & \multicolumn{2}{|c|}{$7.0(1-11)^{b}$} & $6.0(1-11)$ \\
\hline \multirow[t]{2}{*}{ Age, mean (SD), years } & NR & \multicolumn{2}{|c|}{$6.4(3)$} & \multirow{2}{*}{\multicolumn{2}{|c|}{ NR }} & $6.0(2.7)$ \\
\hline & & NR & NR & & & \\
\hline $\begin{array}{l}\text { Patients in prophylaxis } \\
\text { before enrollment, \% }\end{array}$ & $88.7^{\circ}$ & \multicolumn{2}{|c|}{$78.40^{d}$} & \multicolumn{2}{|c|}{$71.4^{\text {be }}$} & $92.4^{4}$ \\
\hline
\end{tabular}

Table VI. Baseline characteristics (subjects aged <12)

$\mathrm{NR}=$ not reported

a Sample includes 84 subjects ( 3 received on-demand treatment and 81 prophylaxis). Among patients on prophylaxis, 65 achieved $\geq 50$ exposure days and

1 patient was excluded due to inhibitor development

${ }^{b}$ The data refers to all subjects, including those in the on-demand regimen $(n=3)$

c Before enrollment, $88.7 \%$ and $11.3 \%$ of subjects received prophylaxis and on-demand treatment, respectively

Before enrollment, $78.4 \%$ and $21.6 \%$ of subjects received prophylaxis and on-demand treatment, respectively

e Before enrollment, $71.4 \%$ and $28.6 \%$ of subjects received prophylaxis and on-demand treatment, respectively

'Before enrollment, $92.4 \%$ and $7.6 \%$ of subjects received prophylaxis and on-demand treatment, respectively

\begin{tabular}{|c|c|c|c|c|c|c|}
\hline Study & A-LONG KIDS & \multicolumn{2}{|c|}{ LEOPOLD KIDS } & \multicolumn{2}{|c|}{ AFFINITY KIDS } & $\begin{array}{l}\text { PROLONG-ATE } \\
\text { KIDS }\end{array}$ \\
\hline Drug & Efmoroctocog alfa & \multirow{2}{*}{\multicolumn{2}{|c|}{$\begin{array}{l}\text { Octocog alfa } \\
\text { Prophylaxis }\end{array}$}} & \multirow{2}{*}{\multicolumn{2}{|c|}{$\begin{array}{c}\text { Lonoctocog alfa } \\
\text { Prophylaxis }\end{array}$}} & Rurioctocog alfa pegol \\
\hline Regimen & Prophylaxis & & & & & Prophylaxis \\
\hline $\begin{array}{l}\text { Frequency of } \\
\text { administration }\end{array}$ & - & $\begin{array}{l}2 \text { times per } \\
\text { week }\end{array}$ & $\begin{array}{l}>2 \text { times } \\
\text { per week }\end{array}$ & $\begin{array}{c}2 \text { times per } \\
\text { week }\end{array}$ & $\begin{array}{l}>2 \text { times } \\
\text { per week }\end{array}$ & - \\
\hline \multirow{2}{*}{$\begin{array}{l}\text { Patients with target } \\
\text { joints, \% }\end{array}$} & \multirow[t]{2}{*}{$18.3 \%$} & \multicolumn{2}{|c|}{$27.5 \%$} & \multirow{2}{*}{\multicolumn{2}{|c|}{$N R$}} & \multirow[t]{2}{*}{$21.2 \%$} \\
\hline & & NR & NR & & & \\
\hline $\begin{array}{l}\text { Bleeds in last } 12 \\
\text { months, median (IQR), } \\
n\end{array}$ & $2.0(0-36)$ & \multicolumn{2}{|c|}{$4.0(0-55)^{\mathrm{a}}$} & \multicolumn{2}{|c|}{ NR } & NR \\
\hline $\begin{array}{l}\text { Joint bleeds in last } \\
12 \text { months, median } \\
\text { (range), } \mathrm{n}\end{array}$ & $\begin{array}{c}8.0(1.0-28.0)(\mathrm{TJ})-2.0 \\
(0.0-36.0)(\text { no TJ) }\end{array}$ & \multicolumn{2}{|c|}{$0.0(0-33)$} & \multicolumn{2}{|c|}{$N R$} & NR \\
\hline
\end{tabular}

Table VII. Baseline orthopedic status (subjects aged <12)

$\mathrm{NR}=$ not reported

a 1 (0-55) in subjects who received prophylaxis before enrollment, 10 (4-49) in subjects treated on-demand before enrollment

per week, at the discretion of the clinician and depending on the characteristics of each patient; $53.1 \%$ of the patients on prophylaxis received the treatment twice a week, $30.9 \%$ three times per week and the remaining $16.0 \%$ every other day or according to other regimens. In the PROLONG-ATE KIDS study [20], which assessed the efficacy of rurioctocog alfa pegol, 66 patients received twice-weekly prophylaxis, at a dosage of 40-60 IU/kg.

The sample size was well balanced between the studies. With regard to the baseline characteristics, a lower proportion of patients already on prophylaxis before the enrollment was reported in the studies LEOPOLD KIDS and AFFINITY KIDS [16,18] (Table VI). An adequate and detailed description of the baseline orthopedic status was often not provided, although it is an important predictor of outcome, especially when dealing with pediatric patients. Table VII reports the lack of information about the joint status of the patients involved in the various studies. LEOPOLD KIDS [16] is the most complete study in terms of information on the clinical characteristics of the patients enrolled. The proportion of patients with target joints is higher in LEOPOLD KIDS [16] than in the other studies [13,20]. In the AFFINITY KIDS 


\begin{tabular}{|c|c|c|c|c|c|c|}
\hline Study & A-LONG KIDS & \multicolumn{2}{|c|}{ LEOPOLD KIDS } & \multicolumn{2}{|c|}{ AFFINITY KIDS } & PROLONG-ATE KIDS \\
\hline Drug & Efmoroctocog alfa & \multicolumn{2}{|c|}{ Octocog alfa } & \multicolumn{2}{|c|}{ Lonoctocog alfa } & Rurioctocog alfa pegol \\
\hline Regimen & Prophylaxis & \multicolumn{2}{|c|}{ Prophylaxis } & \multicolumn{2}{|c|}{ Prophylaxis } & Prophylaxis \\
\hline $\begin{array}{l}\text { Frequency of } \\
\text { administration }\end{array}$ & - & $\begin{array}{l}2 \text { times } \\
\text { per week }\end{array}$ & $\begin{array}{l}>2 \text { times } \\
\text { per week }\end{array}$ & $\begin{array}{l}2 \text { times } \\
\text { per week }\end{array}$ & $\begin{array}{l}>2 \text { times } \\
\text { per week }\end{array}$ & - \\
\hline \multirow{2}{*}{$\begin{array}{l}\text { Follow-up, median } \\
\text { (range), months }\end{array}$} & \multirow[t]{2}{*}{6.1} & \multirow{2}{*}{\multicolumn{2}{|c|}{$6.0(4.5-5.5)$}} & \multicolumn{2}{|c|}{5.6} & 6.0 \\
\hline & & & & \multicolumn{2}{|c|}{ NR } & NR \\
\hline \multirow{2}{*}{$\begin{array}{l}\text { Bleeds per year, median } \\
\text { (IQR), n }\end{array}$} & \multirow[t]{2}{*}{ NR } & \multicolumn{2}{|c|}{$1.9^{a}(0-6.0)$} & \multicolumn{2}{|c|}{$5.5(4.8-6.3)$} & NR \\
\hline & & & & $\begin{array}{c}6.2 \\
(5.2-7.4)\end{array}$ & $\begin{array}{c}5.8 \\
(4.5-7.4)\end{array}$ & \\
\hline \multirow[t]{2}{*}{ ABR, median (IQR) } & \multirow[t]{2}{*}{$2.0(0.0-4.0)$} & \multirow{2}{*}{\multicolumn{2}{|c|}{$1.9(0.0-6.0)$}} & \multicolumn{2}{|c|}{$3.7(0.0-7.2)$} & $2.0(0.0-3.9)$ \\
\hline & & & & $\begin{array}{c}4.4 \\
(2.3-7.2)\end{array}$ & $\begin{array}{c}2.3 \\
(0.0-11.6)\end{array}$ & \\
\hline ABR, mean (SD) & NR & \multicolumn{2}{|c|}{ NR } & \multicolumn{2}{|c|}{ NR } & NR \\
\hline $\begin{array}{l}\text { ABR, negative binomial } \\
\text { model }(95 \% \mathrm{Cl})\end{array}$ & NR & \multicolumn{2}{|c|}{ NR } & \multicolumn{2}{|c|}{ NR } & $3.0(2.2-4.2)$ \\
\hline $\begin{array}{l}\text { Joint bleeds, median } \\
\text { (IQR), n }\end{array}$ & $0.0(0.0-0.0)^{\mathrm{B}}$ & \multicolumn{2}{|c|}{ NR } & \multicolumn{2}{|c|}{ NR } & NR \\
\hline \multirow{2}{*}{$\begin{array}{l}\text { Joint bleed, mean }(95 \% \\
\text { IC), n }\end{array}$} & \multirow[t]{2}{*}{ NR } & \multirow{2}{*}{\multicolumn{2}{|c|}{ NR }} & \multicolumn{2}{|c|}{$3.3(2.7-3.9)$} & NR \\
\hline & & & & $\begin{array}{c}3.8 \\
(3.1-4.8)\end{array}$ & $\begin{array}{c}3.1 \\
(2.2-4.4)\end{array}$ & \\
\hline \multirow[t]{2}{*}{ AJBR, median (IQR) } & \multirow[t]{2}{*}{ NR } & \multicolumn{2}{|c|}{ NR } & \multicolumn{2}{|c|}{$1.6(0.0-4.9)$} & $0.0(0.0-1.9)$ \\
\hline & & & & $\begin{array}{c}1.9 \\
(0.0-4.6)\end{array}$ & $\begin{array}{c}0.8 \\
(0.0-5.3)\end{array}$ & \\
\hline \multirow{2}{*}{$\begin{array}{l}\text { AJBR, negative binomial } \\
\text { model }(95 \% \mathrm{CI})\end{array}$} & \multirow[t]{2}{*}{ NR } & $0.0(C$ & $-2.0)^{c}$ & & & $1.1(0.6-1.9)$ \\
\hline & & & NR & & & \\
\hline Subjects with 0 bleeds, \% & 46.4 & & & & & 38.0 \\
\hline & & NR & NR & & & NR \\
\hline
\end{tabular}

Table VIII. Results $-A B R$ (subjects aged <12)

$\mathrm{NR}=$ not reported

a The data reported in the study is an annualized estimate (follow-up <12) and coincides with the median ABR

b $0.0(0.0-0.0)$ spontaneous joint bleeds and $0.0(0.0-2.0)$ post-trauma bleeds

${ }^{\circ} 0.0(0.0-2.0)$ joint bleeds and $0.0(0.0-0.0)$ spontaneous bleeds

${ }^{d}$ The data refers only to subjects who did not developed inhibitor before and during the study $(n=19)$. Authors declare that this value is similar to the one obtained on all subjects who underwent prophylaxis with lonoctocog alfa during the study

study [18], no information was provided on the joint status of the patients at baseline. The number of bleeds in the 12 months prior to enrollment was higher in LEOPOLD KIDS than in A-LONG KIDS. The duration of follow-up in the patients receiving prophylaxis was approximately 6 months for all studies (Table VIII).

The median ABR was the primary clinical efficacy outcome in all studies. Only in the PROLONG-ATE KIDS study [20], the ABR was reported as an estimate, obtained using a negative binomial model (Table VIII). The patients in the LEOPOLD KIDS [16] and AFFINITY KIDS [18] studies reported the lowest (1.9, IQR: 0.0-6.0) and highest (3.7, IQR: 0.0-7.2) median ABR, respectively (Table VIII).

In terms of consumption, the reported median weekly dose for the various rFVIII products ranged from 79.0 to $97.5 \mathrm{IU} / \mathrm{kg}$, and did not differ significantly between LEOPOLD KIDS and A-LONG KIDS $[13,16]$ (Table IX), despite prophylaxis having different infusion regimens.

Figure 2 shows the relationship between the ABR and weekly consumption attributable to each of the rFVIII products included in the analysis, and highlights the absence of a correlation between ABR and consumption of rFVIII $\left(\mathrm{R}^{2}=0.056\right)$ also in the pediatric population. The median weekly consumption of octocog alfa was higher than lonoctocog alfa and efmoroctocog alfa, but lower than rurioctocog alfa pegol $[13,16,18,20]$. The lowest ABR was reported in LEOPOLD KIDS [16], although it did not differ significantly from that attributable to the other rFVIII products. 


\begin{tabular}{|c|c|c|c|c|c|c|}
\hline Study & A-LONG KIDS & \multicolumn{2}{|c|}{ LEOPOLD KIDS } & \multicolumn{2}{|c|}{ AFFINITY KIDS } & PROLONG-ATE KIDS \\
\hline Drug & Efmoroctocog-alfa & \multicolumn{2}{|c|}{ Octocog-alfa } & \multicolumn{2}{|c|}{ Lonoctocog-alfa } & Rurioctocog-alfa pegol \\
\hline Regimen & Prophylaxis & \multicolumn{2}{|c|}{ Prophylaxis } & \multicolumn{2}{|c|}{ Prophylaxis } & Prophylaxis \\
\hline $\begin{array}{l}\text { Frequency of } \\
\text { administration }\end{array}$ & - & $\begin{array}{l}2 \text { times } \\
\text { per week }\end{array}$ & $\begin{array}{l}>2 \text { times } \\
\text { per week }\end{array}$ & $\begin{array}{l}2 \text { times } \\
\text { per week }\end{array}$ & $\begin{array}{l}>2 \text { times } \\
\text { per week }\end{array}$ & - \\
\hline Dosing regimen & $\begin{array}{l}\text { "Twice-weekly infusions } \\
\text { of } 25 \mathrm{IU} \mathrm{kg}^{-1} \text { on Day } 1 \\
\text { and } 50 \mathrm{IU} \mathrm{kg}^{-1} \text { on Day } \\
4 \text {. Adjustments in dose } \\
\text { to a maximum of } 80 \\
\text { IU/Kg" }\end{array}$ & $\begin{array}{l}\text { "25-50 IU K } \\
\geq 2 \text { times }\end{array}$ & eekly" & $\begin{array}{l}\text { "15 to } 50 \text { Il } \\
\text { every } 2^{\text {nd }} d \\
\text { times per } \\
\text { a dose ano } \\
\text { determinec } \\
\text { investigato } \\
\text { historical } F \\
\text { and availak }\end{array}$ & $\begin{array}{l}\mathrm{kg}^{-1} \\
\text { y or } 2-3 \\
\text { ek or at } \\
\text { frequency } \\
\text { by the } \\
\text { based on } \\
\text { III dosing } \\
\text { e PK data" }\end{array}$ & $\begin{array}{l}\text { "Twice-weekly prophylaxis } \\
\text { (in } 3-4 \text { days intervals) } \\
\text { with } 40-60 \mathrm{IU} \mathrm{kg}^{-1 "}\end{array}$ \\
\hline $\begin{array}{l}\text { Weekly consumption, } \\
\text { median (range), IU/Kg }\end{array}$ & $88.1(80.3-103.1)^{a}$ & $90.1(56$ & -154.7) & & & 97.5 \\
\hline $\begin{array}{l}\text { Weekly consumption, } \\
\text { mean (SD), IU/Kg }\end{array}$ & NR & & & & & NR \\
\hline $\begin{array}{l}\text { Annual consumption, } \\
\text { median (range), IU/Kg }\end{array}$ & NR & & & & 9.0 & NR \\
\hline $\begin{array}{l}\text { Annual consumption, } \\
\text { mean (SD), IU/Kg }\end{array}$ & NR & & & & & NR \\
\hline
\end{tabular}

Table IX. Results - Consumptions (subjects aged <12)

$\mathrm{NR}=$ not reported

a The data refers to subjects in a twice weekly prophylaxis, excluding 2 subjects who had received a variable interval regimen

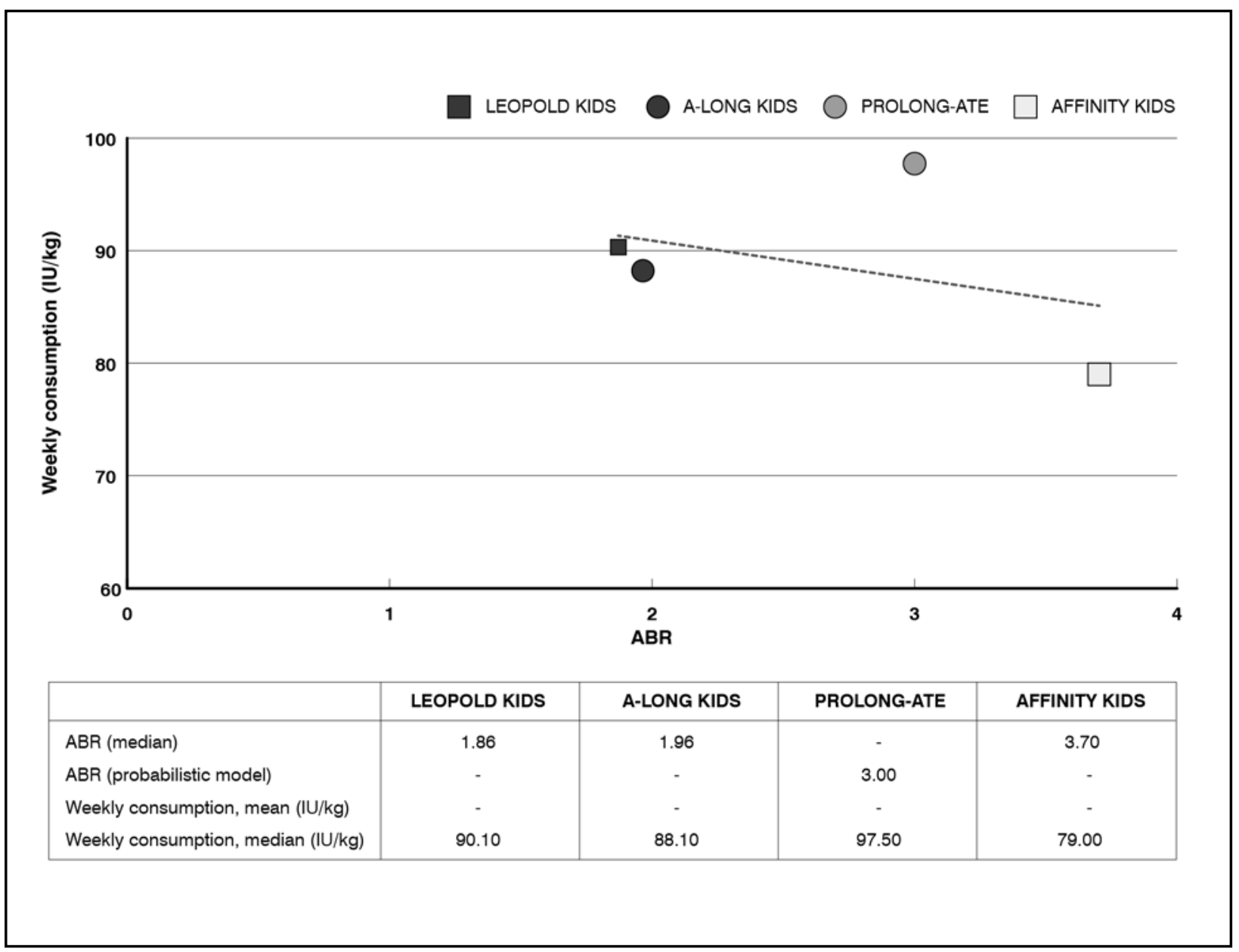

Figure 2. Results - Consumptions and ABR (subjects aged <12)

Note: the dimension of the indicator is directly proportional to the number of subjects enrolled in the study 


\section{DISCUSSION}

Hemophilia $\mathrm{A}$ is undergoing an important change in the management and treatment of patients. While on one hand new products with promising features are appearing on the horizon, on the other there is a need to have tools by which clinicians can guide their therapeutic choices. After over 40 years of clinical experience in the field of hemophilia, prophylaxis is now recognized as the only therapeutic approach able to modify the natural course of the disease, preventing joint damage [7]. New drugs have recently become available, and the extent of clinical evidence has grown (and is likely to further increase). Nevertheless, due to the rarity of the disease, it is still complex to conduct head-to-head studies to compare and establish superiority of one product over another. Therefore, the critical evaluation of the individual trials remains a useful approach for clinicians in order to guide their choices.

This analysis evaluated the pivotal studies of the rFVIII products registered in Europe within the first half of 2018 for the treatment and prophylaxis of patients with hemophilia A without inhibitor. Compared to a previous paper [3], this analysis included products with improved pharmacokinetic profile and a dose regimen based also on a twice weekly schedule, and examined the evidence collected among the entire population (pediatric, adolescent and adult patients).

Although the knowledge of patients characteristics upon enrollment and an accurate description of the bleeding phenotype are important clinical predictors to allow a more accurate assessment of the outcome and actual clinical benefit, they are often not described in detail in the studies, or are even missing. The studies included in this evaluation have different designs, with only LEOPOLD II [15] (octocog alfa) being a completely randomized trial. In this last study, in fact, the patients were assigned to different treatments in such ways as to exclude any type of influence on the part of the investigating physician and the bleeding phenotype. In general, randomization ensures that the patients characteristics in the various treatment arms are as homogeneous as possible, thereby increasing the likelihood that any potentially confounding variables will be distributed uniformly between the groups compared, but requires a minimum sample size to produce scientifically reliable results to ensure greater robustness. In all of the studies identified, ABR and consumption are significant outcomes, on the basis of which doctors and patients should be able to outline an optimal therapy. However, ABR is calculated differently in each of the studies [3] and, depending on the duration of the studies, the findings are almost always annualized estimates [22]. This, together with the differences in the experimental design and the characteristics of the patients enrolled, significantly limit the possibility of a direct comparison between the various rFVIII products.

In this analysis, even without structural modifications, octocog alfa showed similar results, in terms of annualized bleeding rate, to the other rFVIII products, including extended half-life. Octocog alfa may be a useful treatment option in the prophylaxis of adult, adolescent and pediatric patients with hemophilia $\mathrm{A}$, also in a dose regimen lower than three administrations per week. The efficacy data of octocog alfa are supported by a robust and comprehensive clinical program, well detailed in the literature, which involved both adolescent/adult and pediatric patients. The results reported in the LEOPOLD studies [14,15] are very promising, also in relation to the methods defined in the trial. The LEOPOLD II study [15] has a randomized experimental design that, in addition to playing an important role in ensuring the robustness of the data, minimizes the variables that could affect the results, and which the investigating physician would not be able to eliminate. On the other hand, the results of the clinical studies of the EHL products did not show any convincing evidence of superiority in bleeding reduction of one of the products over the others.

Despite the recent advances in the field of hemophilia, in order to guide doctors towards a therapy focused on the patient's needs and based on solid and comprehensive data, the studies should report more detailed and homogeneous information. Further clinical studies should be conducted to evaluate and confirm the efficacy of prophylaxis with the various rFVIII products in pediatric, adolescent and adult patients. The characteristics of the patients included in the studies, the experimental design, the duration and the methodological approaches used to estimate the efficacy outcomes should also be more homogeneous. In fact, the availability of studies with similar characteristics would reduce the limits that currently do not allow a direct comparison between them. Inevitably, the results of these studies should be integrated with real-life studies, which, together with economic assessments, will allow those who are responsible for making decisions in the healthcare sector to be better informed, especially in such a complex context as hemophilia. Further, other new products (long acting rFVIII, bispecific antibody coupling FX and FIXa, monoclonal antibody against TFPI, siRNA knockdown 
of AT) have been approved or will be evaluated for the market access in Europe in the near future. Our analysis could be used as a reference to assess the trials characteristics and the efficacy and consumption data of these new products.

\section{Funding}

This paper was an indipendent study and financially supported by Bayer S.p.a.

\section{Conflicts of interest}

MNDDM reports grants, personal fees and non-financial support from Pfizer, Novo-Nordisk, and Sobi; grants and personal fees from Shire-Takeda; personal fees from Bayer, outside the submitted work.

LSD has nothing to disclose.

PAC reports personal fees from Roche, Pfizer, and Boehringer Ingelheim; grants from Shire-Takeda, outside the submitted work.

ACM personal fees from Bayer, CSL, NovoNordisk, Roche, Shire, and SOBI, outside the submitted work.

LGM reports grants from Bayer, during the conduct of the study; grants and personal fees from Bayer; grants from

Roche, Baxalta-Shire-Takeda, and Biogen, outside the submitted work.

\section{REFERENCES}

1. Gringeri A, Leissinger C, Cortesi PA, et al. Health-related quality of life in patients with haemophilia and inhibitors on prophylaxis with anti-inhibitor complex concentrate: results from the Pro-FEIBA study. Haemophilia 2013; 19: 736-43; https://doi.org/10.1111/hae.12178

2. Barr RD, Saleh M, Furlong W, et al. Health status and health-related quality of life associated with hemophilia. Am J Hematol 2002; 71: 152-60; https://doi.org/10.1002/ajh.10191

3. D'Angiolella LS, Molinari AC, Cortesi PA, et al. Use of Kovaltry ${ }^{\circledR}$ in patients with Hemophilia A: clinical and economical aspects from the pivotal clinical trials. Farmeconomia. Health economics and therapeutic pathways 2017; 18: 1-4; https://doi.org/10.7175/fe.v18i1.1284

4. Gringeri A, Lundin B, von Mackensen S, et al. A randomized clinical trial of prophylaxis in children with hemophilia A (the ESPRIT Study). J Thromb Haemost 2011; 9: 700-10; https://doi.org/10.1111/j.1538-7836.2011.04214.x

5. Advate - Summary of Product characteristics. Available at: https://www.ema.europa.eu/ en/documents/product-information/advate-epar-product-information_it.pdf (Last access March 2019)

6. Srivastava A, Brewer AK, Mauser-Bunschoten EP, et al. Guidelines for the management of hemophilia. Haemophilia 2013; 19: e1-47; https://doi.org/10.1111/j.1365-2516.2012.02909.x

7. Mannucci PM, Mancuso ME, Franchini M. Tailoring hemostatic therapies to lower inhibitor development in previously untreated patients with severe hemophilia A. J Thromb Haemost 2016; 14: 1330-6; https://doi.org/10.1111/jth.13356

8. EMA. Guideline on the clinical investigation of recombinant and human plasma-derived factor VIII products. EMA/CHMP/BPWP/144533/2009 rev. 2. 2018. Available at: https:// www.ema.europa.eu (Last access June 2019)

9. Castaman G. The benefits of prophylaxis in patients with hemophilia B. Expert Rev Hematol 2018; 11: 673-83; https://doi.org/10.1080/17474086.2018.1489719

10. Herbert RD, Broderick CR, Barnes C, et al. Optimization of prophylaxis for hemophilia A. PLoS One 2018; 13: e0192783; https://doi.org/10.1371/journal.pone.0192783

11. Pocoski J, Li N, Ayyagari R, Church N, et al. Matching-adjusted indirect comparisons of efficacy of BAY 81-8973 vs two recombinant factor VIII for the prophylactic treatment of severe hemophilia A. J Blood Med 2016; 7: 129-37; https://doi.org/10.2147/JBM.S104074

12. Mahlangu J, Powell JS, Ragni MV, et al. Phase 3 study of recombinant factor VIII Fc fusion protein in severe hemophilia A. Blood 2014; 123: 317-25; https://doi.org/10.1182/ blood-2013-10-529974

13. Young G, Mahlangu J, Kulkarni R, et al. Recombinant factor VIII Fc fusion protein for the prevention and treatment of bleeding in children with severe hemophilia A. J Thromb Haemost 2015; 13: 967-77; https://doi.org/10.1111/jth.12911 
14. Saxena K, Lalezari S, Oldenburg J, et al. Efficacy and safety of BAY 81-8973, a full-length recombinant factor VIII: results from the LEOPOLD I trial. Haemophilia 2016; 22: 706-12; https://doi.org/10.1111/hae.12952

15. Kavakli K, Yang R, Rusen L, et al. Prophylaxis vs. on-demand treatment with BAY 81-8973, a full-length plasma protein-free recombinant factor VIII product: results from a randomized trial (LEOPOLD II). J Thromb Haemost 2015; 13: 360-9; https://doi.org/10.1111/jth.12828

16. Ljung R, Kenet G, Mancuso ME, et al. BAY 81-8973 safety and efficacy for prophylaxis and treatment of bleeds in previously treated children with severe haemophilia A: results of the LEOPOLD Kids Trial. Haemophilia 2016; 22: 354-60; https://doi.org/10.1111/hae.12866

17. Mahlangu J, Kuliczkowski K, Karim FA, et al. Efficacy and safety of rVIII-SingleChain: results of a phase 1/3 multicenter clinical trial in severe hemophilia A. Blood 2016; 128 : 630-7; https://doi.org/10.1182/blood-2016-01-687434

18. Stasyshyn O, Djambas Khayat C, Iosava G, et al. Safety, efficacy and pharmacokinetics of rVIII-SingleChain in children with severe hemophilia A: results of a multicenter clinical trial. J Thromb Haemost 2017; 15: 636-44; https://doi.org/10.1111/jth.13647

19. Konkle BA, Stasyshyn O, Chowdary P, et al. Pegylated, full-length, recombinant factor VIII for prophylactic and on-demand treatment of severe hemophilia A. Blood 2015; 126 : 1078-85; https://doi.org/10.1182/blood-2015-03-630897

20. Mullins ES, Stasyshyn O, Alvarez-Román MT, et al. Extended half-life pegylated, fulllength recombinant factor VIII for prophylaxis in children with severe haemophilia A. Haemophilia 2017; 23: 238-46; https://doi.org/10.1111/hae.13119

21. Mahlangu J, Young G, Hermans C, et al. Defining extended half-life rFVIII-A critical review of the evidence. Haemophilia 2018; 24: 348-58; https://doi.org/10.1111/hae.13438

22. Chai-Adisaksopha $\mathrm{C}$, Hillis $\mathrm{C}$, Thabane $\mathrm{L}$, et al. A systematic review of definitions and reporting of bleeding outcome measures in haemophilia. Haemophilia 2015; 21: 731-5; https://doi.org/10.1111/hae.12750 